\title{
A ATUAÇÃO DO PEDAGOGO EM ESPAÇOS NÃO ESCOLARES: GESTÃO POSSIBILIDADES E DESAFIOS
}

\author{
THE PEDAGOGUE'S PERFORMANCE IN NON-SCHOOL SPACES: \\ MANAGEMENT POSSIBILITIES AND CHALLENGES
}

\author{
Franciely Souza Modesto ${ }^{1}$ \\ Silvanis dos Reis Borges Pereira ${ }^{2}$
}

\begin{abstract}
RESUMO: Este trabalho tem por objetivo analisar o papel do pedagogo frente a gestão de atividades exercidas no campo não formal, retratando os desafios e as possibilidades presentes na atuação. A pedagogia extraescolar surgiu para atender as necessidades da sociedade em constante evolução, tendo como público alvo crianças, jovens, adultos e idosos, atendendo prioritariamente a parcela socialmente mais vulnerável. Dessa forma o pedagogo firma seu papel na pedagogia extraescolar como peça fundamental no processo de ensino e aprendizagem dos âmbitos não escolares de forma global, estando devidamente preparado profissionalmente, como agente que desperta o desejo por mudança no indivíduo, que passa a se conhecer enquanto cidadão crítico e capaz de refletir sobre as próprias atitudes. A pesquisa está estruturada como qualitativa, descritiva sendo organizada através do método de revisão bibliográfica e documental, que se deu por meio da seleção de materiais referentes à problemática estudada, publicados em periódicos, artigos, revistas e livros disponíveis na biblioteca da Unitins. Refletir sobre o papel do pedagogo frente a gestão se torna pertinente à medida que novas perspectivas se delineiam a respeito de sua atuação com as possibilidades de utilização das práticas pedagógicas, de modo que as mesmas sejam significativas, contribuindo para que os desafios se tornem possibilidades de inovação na sociedade e para ela, enfatizando o exercício da função pedagógica.
\end{abstract}

Palavras-chave: $O$ papel do pedagogo. Espaços não escolares. Possibilidades e desafios; Extraescolar.

ABSTRACT: This work aims to analyze the role of the pedagogue in relation to the management of activities carried out in the non-formal field, portraying the challenges and possibilities present in the performance. Out-of-school pedagogy emerged to meet the needs of a constantly evolving society, targeting children, youth, adults and the elderly, giving priority to the socially most vulnerable. In this way, the pedagogue establishes his role in out-of-school pedagogy as a fundamental part of the teaching and learning process in non-school areas in a global way, being properly prepared professionally, as an agent that awakens the desire for change in the individual, who comes to know himself as a citizen critical and able to reflect on their own attitudes. The research is structured as qualitative, descriptive being organized through the method of bibliographic and documentary review, which took place through the selection of materials related to the studied problem, published in periodicals, articles, magazines and books available in the Unitins library. Reflecting on the role of the pedagogue in relation to

1 Graduanda do curso de Pedagogia da Universidade Estadual do Tocantins-UNITINS (Campus Araguatins).E-mail: franciellymodesto4i@gmail.com.

${ }^{2}$ Mestranda em Educação na UFT, Professora/Pesquisadora, Câmpus ARAGUATINS da UNITINS. Email: silvanisborges@hotmail.com. 
management becomes pertinent as new perspectives are outlined regarding his performance with the possibilities of using pedagogical practices, so that they are meaningful, contributing so that the challenges become possibilities of innovation in society and for it, emphasizing the exercise of the pedagogical function.

Keywords: The role of the pedagogue. Non-school spaces. Possibilities and challenges. Extrasolar.

\section{INTRODUÇÃO}

A pedagogia no espaço não escolar ganhou força através da necessidade da presença do profissional pedagogo em diversos órgãos governamentais e não governamentais, ele que desenvolve um papel essencial como articulador no processo de ensino e aprendizagem nas mais variadas instituições. O exercício educativo está presente em todos os campos sociais, preparando o cidadão para o convívio social, a pedagogia abre uma gama de possibilidades para a atuação não formal promovendo um leque de oportunidades profissionais.

A atuação do pedagogo em espaços não escolares aqui discutida é desempenhada através da gestão, planejando, executando, coordenando e avaliando as atividades. A ação de gerir do pedagogo nesses espaços abrange diversos setores administrativos, com objetivo educativos e sociais, buscando subsidiar a prática com a utilização de estratégias metodológicas, como ações de mediação no processo de ensino e aprendizagem incluindo o gerenciamento de projetos. Nesta perspectiva ele busca promover um serviço social viabilizado pela necessidade de intervenção diante de situações de convívio, atrito ou reabilitação comunitária.

A problemática investigada, visa responder a seguinte indagação: Como se efetiva a atuação da gestão do pedagogo nos espaços não escolares?

O trabalho tem como objetivo geral refletir sobre a atuação do pedagogo na gestão em espaços não escolares. Como objetivos específicos: I) Descrever sobre a Pedagogia em Espaços não escolares; II) Conhecer o papel do pedagogo na gestão em espaços não escolares; III) Compreender as possibilidades e desafios do pedagogo frente a gestão dos espaços não escolares.

Neste contexto, sua atuação é relevante, conforme a necessidade de compreender a pedagogia além do campo formal, ressaltando uma gama de possibilidades profissionais pertinentes à ele, bem como atividades abrangentes no desempenho pedagógico, buscando comtemplar a educação, favorecendo a sociedade. É preciso compreender o papel do pedagogo dentro das instituições para que o direito à ocupação do espaço seja atendido e principalmente reconhecido diante da sua importância no processo de ensino aprendizagem no exercício da sua função na gestão.

A pesquisa qualitativa, descritiva, executada através da pesquisa bibliográfica, adquiridas 
a partir da seleção de artigos científicos publicados em periódicos e livros. Para fundamentar as argumentações, foram citados os seguintes teóricos: Libâneo (1999); Gohn (2006); Dias (2019) entre outros.

Dessa forma, espera-se que este trabalho possa contribuir em debates que abordem a temática, dando ênfase a gestão pedagógica não escolar, constituindo-se como prática fundamental para a formação do cidadão crítico e reflexivo.

\section{A PEDAGOGIA EM ESPAÇOS NÃO ESCOLARES: CONCEITOS E PERSPECTIVAS}

A educação não formal por vezes é associada a educação formal, por serem consideradas complementares, e ainda, indissociáveis, pois a formal depende do campo e fundamentação curricular e burocrática, enquanto a não formal possui estratégias de ensino fora do campo escolar de maneira flexível. É possível considera-las como essenciais para o processo formativo educacional e social.

A educação não formal acontece fora do sistema formal, segundo Almeida (2014, p. 2) ela é "Considerada uma modalidade de ensino, se desenvolve nos espaços não convencionais de educação". Objetivando desenvolver o ensino aprendizagem de maneira integral fora do âmbito escolar, sendo ainda pouco compreendida pela comunidade, o pedagogo no espaço não formal, busca atender a população, principalmente àqueles que se encontram fragilizados. Proporcionando atividades extraescolares reintegrando crianças, jovens, adultos e idosos, garantindo um bem-esta social aos integrantes.

Para conceituar a educação fora das instituições de ensino formais pode-se pensar em uma educação que rompe os muros da escola e a perpassa, permitindo então uma alternância entre tempos e locais, com ferramentas e adaptações especificas para atender as necessidades de cada público com uma organização diversificada. Desse modo "O conceito de educação não formal inclui o de educação não escolar, sem implicar em sinônimos, portanto. Embora possua uma organização e uma estrutura (distinta da escola) ". (MOREIRA; FALCO 2017, p.264)

A educação não formal parte do pressuposto de formar um cidadão apto para atuar em sociedade estabelecendo interações entre os grupos, integrando o sujeito dentro das suas capacidades, envolvendo seus hábitos e culturas, o que possibilita a troca de experiências dentro do processo, contraposta ao ensino formal onde trabalha-se com uma gama de suporte curricular e burocrático, no entanto á educação aplicada nos campos não formais pode contribuir significativamente para a educação formal. Para Anelo e Souza (2012):

A educação não formal fundamenta-se no critério de solidariedade e identificação de interesses comuns e é parte do processo de construção da cidadania coletiva do grupo. Assim, os conhecimentos são produzidos 
considerando os modos de agir em grupo, o resgate de sentimento de autovalorização, a percepção da vida e suas adversidades, o aprendizado e a compreensão do mundo no contexto em que vivem. Diferente da educação formal, que tem objetivos relativos ao ensino e a aprendizagem, de conteúdos sistematizados por lei, busca formar indivíduos ativos, desenvolver habilidades e competências cidadãs. (ANELO E SOUZA, 2012, p.4I).

Nesse contexto a educação não formal trabalha de maneira alternada em diversos meios, com exercícios em conjunto, permitindo uma aproximação dos envolvidos promovendo troca de experiências e vivencias, dentro da sua cultura. Segundo Lopes et al. (2017, p.04) “[...] em ambientes e situações interativas construídas coletivamente, sendo uma educação complementar, tendo a intencionalidade na ação no ato de participar” fora da obrigatoriedade burocrática do ensino regular, ocorrendo de maneira espontânea interdisciplinar e educativa.

A pedagogia é pouco conhecida dentro dos campos não formais, pois a sociedade a entende como curso de formação exclusivamente para atuação docente, porém, já faz um tempo que essa perspectiva vem sofrendo modificações e reorganizações. A atuação do pedagogo nos campos não formais se faz necessária devido a relevância de suas contribuições pedagógicas e profissionais, contrariando o pensamento de pessoas que idealizam a pedagogia como “[...], um curso somente para se atuar dentro de escolas formais. O que não é verdade, a pedagogia em espaços não escolares é muito trabalhada nos dias atuais. ” (PEREIRA, 20I6, p. I2).

A pedagogia assim como a educação, ganhou uma nova roupagem ao longo do tempo, juntamente com as tecnologias e necessidades da sociedade, o que antes era considerado objeto de estudo tendo em vista a escola como único campo de condução do processo de ensino e aprendizagem perpassou os muros da instituição dentro do sistema formal. Neste sentido para Almeida e Oliveira (2014):

Nos anos de 1990 o grande destaque para a educação não formal foram mudanças que aconteceram nas áreas da economia, na sociedade e no trabalho. A aprendizagem em grupo passou a ser valorizada, incluindo os valores culturais, a aprendizagem e habilidades que são adquiridos fora dos espaços formais de educação. (ALMEIDA; OLIVEIRA, 2014, p.6)

Nesta perspectiva, o ensino acontece em diferentes espaços por meio da mediação de um profissional inteiramente capacitado para propor as atividades e promover o desenvolvimento das competências e habilidades do indivíduo em questão. Segundo Gonçalves e Correa (2014, p.196), “[...], em qualquer espaço escolar é necessário um profissional que esteja preparado para lidar com a pratica pedagógica sistematizada ou não”. A pedagogia em espaços não formais objetiva preparar o sujeito assim como a instituição de ensino formal, mas de maneira interdisciplinar buscando complementar a educação escolar.

É sabido que a pedagogia se divide em dois campos de atuação que se classificam dentro do campo escolar e do campo não escolar, ambos com o mesmo objetivo de possibilitar a educação 
ao meio social. De acordo com Libâneo (199, p. 51), "No campo da ação pedagógica extraescolar distinguem-se profissionais que exercem sistematicamente atividades pedagógicas e os que ocupam apenas parte de seu tempo nessas atividades”. Ou seja, existe uma gama de atividades que necessitam a supervisão de um pedagogo em instituições, empresas estatais ou não, de meio período ou em tempo integral.

Dentro da perspectiva da pedagogia nos espaços não escolares, é possível compreender a vasta possibilidade de atuação no campo extraescolar e nos diversos setores, em instituições sistematizadas ou fora delas. Segundo Libâneo (1999), os setores de exercício pedagógicos extraescolar é amplo, podendo concluir que a educação não escolar tem uma variedade de intermediários pedagógicos que trabalham no contexto da vida privada ou social incluindo instituições, famílias, comunidade e outros grupos sociais.

Dentre a atuação pedagógica não escolar existem alguns campos a serem citados como, por exemplo; órgãos, serviços comunitários, empresas, hospitais, centros de reabilitação social e outros, nos quais o pedagogo é introduzido como intermediário dos serviços oferecidos em cada departamento atendendo suas necessidades didáticas pedagógicas de educador, comunicador, didático. Levando o sujeito a uma tomada de atitude pertinente ao seu contexto ou até mesmo uma elevação pessoal como promotor de ações pessoal ou interpessoal. De acordo com Libâneo (1999):

a) Formadores, animadores, instrutores, organizadores, técnicos, consultores, orientadores, que desenvolvem atividades pedagógicas (não-escolar) em órgãos públicos, privados e públicos não-estatais, ligadas as empresas, á cultura, aos serviços de saúde, alimentação, promoção social etc. b) formadores ocasionais que ocupam parte de seu tempo em atividades pedagógicas em órgãos públicos estatais e não-estatais e empresas referentes a transmissão de saberes e técnicas ligados a outra atividade profissional especializada. Trata-se, por exemplo, de engenheiros, supervisores de trabalho, técnicos etc. Que dedicam boa parte de seu tempo a supervisionar ou ensinar trabalhadores no local de trabalho, oriente estagiários etc. (LIBÃNEO, 1999, p. 51 e 52)

Deve-se ressaltar que por muito tempo a pedagogia foi concebida estritamente como formação para atuação na docência, na atualidade a atuação em espaço extraescolar está se afirmando e conquistando reconhecimento, mas é notório que ainda existem dificuldades de posicionamento referentes ao posto do pedagogo frente a essa modalidade. Dessa forma quando esclarecida a função do pedagogo nesse ambiente aumenta-se a procura por profissionais que antes eram dirigidas por profissionais aleatórios. De acordo com Pereira (2016):

Devemos ainda levar em consideração que há alguns anos não era muito comum encontrar profissionais da educação atuando fora das escolas, e que por muito tempo essa atuação fora do âmbito escolar foi vista como desnecessária. Não existia procura e nem tanta divulgação deste trabalho, sendo então realizado por profissionais de outras áreas. $\mathrm{O}$ pedagogo era visto apenas como 
um profissional cuja atuação era restrita às áreas educacionais, para a educação formal as crianças, não tendo oportunidade de atuar em trabalhos diferenciados como acontece na atualidade. (PEREIRA, 2016, p.io)

Portanto é preciso compreender a educação dentro e fora do ambiente escolar. Educar é o ato de compartilhar conhecimentos, haja vista que a partilha se efetiva de diversas maneiras e em diferentes locais, Paulo Freire, por exemplo, não se ateve a uma sala de aula, o que não foi obstáculo suficiente para que não houvesse aprendizado, assim conseguiu alfabetizar adultos levando em consideração o conhecimento popular, pois segundo Freire (1996, p.ı2) “ensinar não é transferir conhecimento, mas criar as possibilidades para a sua produção ou a sua construção". Partindo deste pressuposto a educação informal é constituída na pratica de ensino e aprendizagem independente de espaço físico e institucional, pois o ato educativo perpassa a educação formal.

Ensinar e aprender podem ser considerados conjuntos de componentes do processo de ensino e aprendizagem, podendo existir tanto juntos como também separados é possível o indivíduo aprender de forma autônoma através da experiência ou outros meios. Para Freire (I996, p. 12) "Ensinar inexiste sem aprender e vice-versa e foi aprendendo socialmente que, historicamente, mulheres e homens descobriram que era possível ensinar”. O ser humano tem a capacidade de aprender e ensinar, o aprendizado acontece em casa quando a mãe ensina o filho a fechar a torneira, limpar a casa tratar bem as visitas, são variáveis entre ações simples e complexas onde existir alguém disposto a ensinar e a aprender haverá educação sendo dentro ou fora da escola, pois o ser humano é construído por diversos saberes.

Deste modo, a educação se faz presente durante toda a vida humana, constituída no seio da família e da escola, objetivando principalmente o compartilhamento mútuo do conhecimento, é sabido que a escola não é o único campo onde ocorre o ato educativo. A educação vem passando por mudanças, a escola, passa então a complementar as atividades educacionais e sociais, por meio da educação extraescolar, que pode acontecer em lugares diversificados e distintos, trazendo novos espaços de construção do conhecimento. De acordo com Antkiewicz e Costa (2019):

A educação sofre mudanças em seu conceito, pois deixa de ser restrita ao processo ensino-aprendizagem em espaços formais, se transpondo aos muros da escola, para acontecer em locais diferentes, em diversas situações sociais e diversos segmentos, como: ONGs, sindicatos, clubes, igrejas, empresas, hospitais, presídios etc. Abre-se um novo espaço para a educação, dando uma estrutura interessante à Educação Não Formal. (ANTKIEWICZ; COSTA, 2019, p. 74)

O processo formativo do campo não formal aqui exposto favorece a educação formal, pois o ser humano se faz aprendiz por toda a vida, as duas modalidades são complementares, porém distintas, proporcionando aprendizados sobre diversas áreas do conhecimento, 
possibilitando diferentes contribuições para a formação do sujeito de maneira integral. É possível implementar a educação fora da escola de maneira prática e didática favorecendo o aprendizado no processo educativo.

\section{I O PAPEL DO PEDAGOGO NA GESTÃO EM ESPAÇOS NÃO ESCOLARES: POSSIBILIDADES DE ATUAÇÃO}

O pedagogo passa por um processo formativo durante a formação profissional, o que contribui para que ele possa se munir com práticas e conhecimentos teóricos para a atuação nos espaços formais e não formais de educação. Nessa perspectiva é valido ressaltar que o pedagogo está apto a atuar nos campos mencionados.

Os autores Ferreira e Medeiros (2012, p. 4), em suas interpretações discutem que, "De acordo ao que cabe à Pedagogia, compreendemos que esta deve preparar os formandos tanto em relação aos conhecimentos teórico-prático, como as ferramentas necessárias para a atuação docente". A pedagogia então tem o objetivo de formar o ser humano e essa formação parte de diversas áreas de conhecimento, inclusive da não formal.

Partindo da perspectiva do Ministério da Educação, através do conselho nacional de educação e o conselho pleno, no uso da resolução no 2 , de $\mathrm{I}^{\circ}$ de julho de 2015, amplia-se na pedagogia a modalidade extraescolar, destacando o grupo de valores e princípios para atuação no espaço não formal ressaltando o meio social e cultural do discente, garantindo os direitos, deveres e a democracia do cidadão para com as práticas educativas pertinentes à atuação pedagógica, tanto nos espaços escolares e não escolares.

O currículo como o conjunto de valores propício à produção e à socialização de significados no espaço social e que contribui para a construção da identidade sociocultural do educando, dos direitos e deveres do cidadão, do respeito ao bem comum e à democracia, às práticas educativas formais e não formais e à orientação para o trabalho. (GARCIA, 2015, p. 2)

Diante da Lei ${ }^{\circ} 9.394$, sancionada em 20 de dezembro de 1996 que estabelece as diretrizes e bases da educação nacional (LDBEN). A educação engloba os métodos de desenvolvimento de diversas áreas da vida do indivíduo, como familiar, humana, profissional, social e cultural. Em vista disso é possível analisar que o que caracteriza a educação não é seu espaço físico, mas o fazer educativo. De forma que possa desenvolver as competências e habilidades do educando. Para Brandão (2007):

Art. ${ }^{\circ}$ - A educação abrange os processos formativos que se desenvolve na vida familiar, na convivência humana, no trabalho, nas instituições de ensino e pesquisa, nos movimentos sociais e organização da sociedade civil e nas manifestações culturais. (BRANDÃO, 2007, p. 17)

Ao citar o campo não escolar fica subentendido o real espaço de atuação e qual o papel do pedagogo diante dele, sendo necessário especificar qual o local fora do ambiente escolar pode ser considerado campo não formal. No entanto, a atividade do meio não formal pode e deve ser 
levada para dentro do campo formal, através de exposições dentro das práticas educativas implicando no ensino aprendizagem através de trocas de experiências, portando práticas educativas extraescolares podem cruzar com as práticas escolares. Para Marques (2012):

Afinal, não escolar são todos os espaços/práticas fora da escola. Campo amplo de atuação, mas, ao mesmo tempo, sem demarcação para a atuação dos pedagogos. Tudo que está fora da escola (não-escolar) pode ser campo de atuação dos pedagogos? Definimos que não. Afinal, podemos realizar práticas educativas em outros espaços que podem/ devem penetrar a escola. Podemos inclusive realizar práticas na escola que se encontram ainda fora das suas regulamentações, do seu currículo, como atividades que envolvem oficinas de leitura, teatro, danças; brinquedotecas, dentre outras. (MARQUES, 2012, p. 4)

A gestão é o ato de gerir, direcionar e administrar. Dentro das instituições escolares é especifico pela referência do diretor, mas faz parte da gestão todos os envolvidos no processo educativo, seja escolar ou não escolar, todo o suporte de profissionais de qualquer função produz com intuito de garantir a qualidade do ensino e aprendizagem. Portanto se aprendemos pelo exemplo todo o ambiente pode educar.

A atuação do pedagogo é essencial nos campos não formais de educação, pois sua formação profissional propõe o papel de formador e mediador da aprendizagem. As práticas metodologias e didática do pedagogo aliadas aos campos não formais podem trazer contribuições para uma aprendizagem significativa, o pedagogo conta com uma visão sistematizada do processo educativo. Diante desta perspectiva são muitos os campos de atuação do pedagogo.

Dentre os campos de atuação cita-se o ramo empresarial, a empresa que se preocupa com os recursos humanos, bem-estar profissional e de atendimento dos funcionários e clientes, reconhece a necessidade de um pedagogo em sua estrutura organizacional. Segundo Pereira (2016, p.I2), “A área empresarial, que exige do pedagogo criar projetos educacionais e culturais para as empresas de diversos setores, como setores de recursos humanos”. O pedagogo que atua em empresas trabalha com projetos de melhoria das relações interpessoais, com formação continuada e auxílio ao desenvolvimento profissional.

Cabe ao pedagogo elaborar metodologias que garanta uma aprendizagem significativa, proporcionando a tomada de decisão por parte do funcionário e um melhor desempenho profissional na realização das atividades. Para Pereira (2016, p.16), “A pedagogia empresarial tem como finalidade observar as habilidades e atitudes necessárias para melhorar o desenvolvimento do funcionário, objetivando melhorar o desempenho do mesmo na melhoria de seu trabalho”. É sabido que um profissional motivado é mais produtivo em sua função, produzindo melhor a empresa obtém lucros e profissionais capacitados.

Dentre outros campos de atuação não escolar existe a pedagogia hospitalar, que visa levar atendimento educacional às crianças em estado de internação, que estão afastadas da escola por 
alguma complicação de saúde. O pedagogo adapta um cronograma relativo ao quadro de saúde do aluno/paciente de acordo com a idade e série, dentro desse espaço ele busca promover o desenvolvimento do aluno e suas habilidades. Para Pereira (2016):

A pedagogia hospitalar tem como objetivo trabalhar com as crianças/adolescentes que se encontram hospitalizados, o que os impossibilita de frequentar uma escola regular. E cabe ao profissional da educação, atuar no ambiente hospitalar de uma forma que possa suprir as necessidades encontradas pelo paciente/aluno. (PEREIRA, 2016, p.13)

O pedagogo atuante no espaço hospitalar deve buscar novas metodologias, que não forcem a criança, de maneira prática e didática, mas que não deixe de ser contextualizada com o processo de ensino. Segundo Pereira (2016, p. 13), o pedagogo "Na área hospitalar deve aprimorar seus métodos educativos, para que o ensino aplicado dentro do hospital seja tão eficaz quanto o de uma escola regular, devendo o professor atuar com atividades lúdicas". Dessa forma trabalhar com atividades lúdicas como filmes, historias, jogos pode favorecer esse processo além de proporcionar alegria e bem-estar ao paciente, que por vezes passa por internações de longo período.

A pedagogia no sistema penitenciário também faz parte dos campos de atuação não formal é de conhecimento geral que a educação é direito de todo cidadão, portanto o presidiário tem o direito ao acesso educacional, partido da mesma metodologia educacional utilizada na educação de jovens e adultos (EJA), pois atende a mesma faixa etária, o processo educativo dentro deste campo deve ser visto como uma reeducação para o resgate desse sujeito. Para Santos (2015, p. 105) "A educação dentro deste ambiente tem que ser vista como uma educação acima de tudo transformadora, com a finalidade de conscientizar os detentos, fazê-los compreender seus deveres". Dentro desse sistema, sua função é baseada em ideias dentro desse sistema, procurando resgatar o indivíduo, consciente dos seus direitos e deveres para atuar em sociedade de forma democrática e participativa.

O pedagogo do sistema penitenciário enfrenta adversidades em relação aos recursos, livros, materiais, onde muitos são adquiridos por meio de doações, considerando o desempenho de sua função de acordo com Santos (2015), leva-se em conta a afirmação de que o pedagogo é o profissional da educação na prática de seu exercício nesse campo de atuação, o qual deve ser entendido como mediador, articulando os conhecimentos culturais e adquiridos dos alunos, proporcionando um ambiente de troca de saberes entre educando e docente, desfazendo o modelo padrão de que o professor é dono do saber.

A atuação do pedagogo no terceiro setor se evidencia por meio das instituições sociais que desenvolvem ações voltadas para a sociedade. Diante no exercício da sua função em ONGs (Instituições Não Governamentais) ele desenvolve projetos como feiras, oficinas, artesanatos, 
grupo de apoio entre outros. Presta serviço didático educacional, busca acoiçados nos casos de instituições não governamentais. Atende diversos públicos como crianças, jovens adolescentes e idosos aproxima os laços familiares e sociais, resgata o bem-estar do indivíduo. Nas visões de Filho e Contreras (20II):

O profissional pedagogo junto às ONGs desenvolve e elabora projetos educativos, planeja ações da instituição, presta suporte pedagógico, busca parcerias, entre outras ações. O trabalho do pedagogo está direcionado a oportunizar novas experiências educativas a crianças, adolescentes, jovens e adultos, auxiliar no fortalecimento do vínculo familiar e comunitário, viabilizar a descoberta de novas potencialidades e fortalecer a autoestima dos sujeitos. (FILHO E CONTRERAS, 2orr, p.roog6)

As ONGs trabalham com intervenções educativas, em sua maioria atendendo uma parcela da população em estado de vulnerabilidade. De acordo com Tavares, Dias e Araújo "As ações educativas que pedagogos executam dentro de ONGs vêm se ampliando e se consolidando em novas possibilidades de trabalho." (TAVARES; DIAS; ARAÚJO, 2015, p. 25).

Os projetos oferecidos como dança, música, aulas extras complementam as horas vagas do sujeito e assim os afasta da rua evitando-se a marginalização social. Ser educador no campo não formal é saber ouvir, refletir, analisar, gerir e acima de tudo entender o ser humano integralmente.

\subsection{O PEDAGOGO FRENTE À GESTÃO DOS ESPAÇOS NÃO ESCOLARES: DESAFIOS}

O pedagogo frente à gestão dos espaços não escolares percorreu por diversos desafios até a chegada da atuação pedagógica fora do ambiente escolar, pois o pedagogo era visto apenas como profissional para a atuação docente. Com a ampliação da pedagogia para os espaços não escolares, buscando atender as necessidades da sociedade surgiu a possibilidade de explorar novos campos de atuação fora do ambiente escolar, pois o pedagogo possui embasamento teórico para promover a ação educativa em diferentes perspectivas e espaços. Para Reis

O pedagogo antes visto apenas em escolas, preocupado com o processo de ensino aprendizagem, agora está em outros locais, como educador social em empresas, hospitais, ONGs, associações, igrejas, eventos formando atualmente um novo campo para o profissional. Afinal, onde houver práticas educativas, se tem uma ação pedagógica exercida por um profissional da educação. Pois não pode-se pensar o pedagogo como conhecedor apenas dos métodos de ensinar, pois o pedagogo lida com a educação como seu todo e suas ramificações, não está restrito apenas ao ensino. (REIS. 2013, p.34).

Diante da perspectiva o papel do pedagogo frente à gestão dos espaços não escolares é possível considerar a gestão como o ato de gerir, administrar e direcionar. Para Libêneo (20oI) 
“A gestão é a atividade pela qual são mobilizados meios e procedimentos para atingir os objetivos da organização, envolvendo, basicamente os aspectos gerenciais e técnicos-administrativos". Dessa maneira o pedagogo na gestão dos espaços não formais parte da tomada de atitude onde norteia os objetivos prévios a serem alcançados administrando as ações estabelecidas.

Partindo do conceito de gestão é notório que o papel do pedagogo se baseia em administrar as ações educativas buscando alcançar objetivos traçados anteriormente com o intuito de desenvolver as capacidades do educando, fora da escola em seus diversos campos. Portanto é possível afirmar que a gestão acontece no exercer da função pedagógica, sendo assim o papel do pedagogo na gestão é administrar as atividades exercendo seu planejamento, exercício e avaliação das atividades propostas nos referidos campos educativos. De acordo com a perspectiva de Dias:

A gestão não é uma mera forma de controle coercitivo na administração, uma mecanização autoritária de controle, todo gestor é parte integrante de um corpo, uma equipe, que busca nas ciências sociais os métodos para uma gestão que atente para o lado humano de seu trabalho e das pessoas que fazem parte deste meio. (DIAS, 2019, p.2)

Diante das possibilidades da gestão da pedagogia nos ambientes não formais afirma Nascimento et al. (2010, p. 63) "as possibilidades estão diretamente ligadas às necessidades de cada local de trabalho. Cabe ao profissional demarcar seu espaço e construir sua forma de trabalho". Todos os campos possuem suas possibilidades e desafios, por esse motivo o profissional precisa estar munido de suporte teórico e prático, assim é importante que o pedagogo tenha uma formação qualificada para uma atuação significativa.

Dentre a formação existe a ética e moral do profissional disposto a desenvolver de forma satisfatória seu trabalho e expressar seu potencial que segundo Nascimento et al (2010) "O que determina o sucesso desse profissional é a sua forma de atuação, seu compromisso com o trabalho e sua relação explícita com a teoria apreendida na sua formação". Ou seja, a formação tem por objetivo preparar o profissional pedagogo para o exercício nos campos formais ou não formais, partindo do suporte teórico e prático, desta maneira tornado o profissional consciente da sua atuação e abrangendo suas possibilidades.

A princípio o ensino não formal possibilita diversas possibilidades como os campos de atuação proporcionando também a flexibilidade metodológica educativa, pois valoriza o conhecimento através das trocas de experiências entre os educandos desta forma facilitando os elos entre indivíduo e sociedade de maneira democrática resgatando o equilíbrio social, além de trazer a transversalidade de formação para o mundo com o objetivo de promover o conhecimento próprio e social, sobre tudo a educação não formal educa o sujeito para a sociedade em seus aspectos transversais. 
De acordo com Gohn:

A educação não- formal capacita os indivíduos a se tornarem cidadãos do mundo, no mundo. Sua finalidade é abrir janelas de conhecimento sobre o mundo que circunda os indivíduos e suas relações sociais. Seus objetivos não são dados a priori, eles se constróem no processo interativo, gerando um processo educativo. (GOHN, 2006, p.29)

Na educação não formal são utilizadas algumas metodologias de ensino, que são trabalhadas em grupos pois é valorizado a interação pessoal e o aprendizado através de trocas de conhecimentos partindo também do pressuposto cultural do indivíduo. Para Gohn (2006, p.32) "O método passa pela sistematização dos modos de agir e de pensar o mundo que circunda as pessoas"”. O método surge a partir da vida cotidiana do sujeito, ou seja, tendo em vista a demanda da comunidade em questão atendendo a carência, necessidades ou desafios do público alvo.

A educação não formal parte de alguns objetivos sendo, responsáveis pelas variedades de possibilidades de atuação dentro desta modalidade, buscando atender as necessidades do público alvo e proporcionar qualidade de vida. Através dela pretende-se desenvolver um cidadão crítico e democrático, que se permite enxergar as individualidades do próximo dentro dos pressupostos culturais, sociais, de justiça social, de igualdade e liberdade. Seus objetivos são semelhantes aos da educação formal, portanto uma é complemento da outra. Pra Gohn os objetivos da educação não formal são os seguintes:

a) Educação para cidadania; b) Educação para justiça social; c) Educação para direitos (humanos, sociais, políticos, culturais, etc.); d) Educação para liberdade; e) Educação para igualdade; f) Educação para democracia; g) Educação contra discriminação; h) Educação pelo exercício da cultura, e para a manifestação das diferenças culturais. (GOHN, 2006, p.32 e 33)

As organizações formadoras de caráter social que buscam maneiras de desenvolver a formação efetiva e integrada com bases nas relações interpessoais e educativas trabalham com projetos didáticos e dinâmicos. Para SeveroI (2015, p.564) "Essa dinâmica educativa se estrutura com base na diversidade de saberes em fluxo nas relações humanas, incorporando múltiplas possibilidades de promoção de aprendizagens significativas”. Tem como finalidade desenvolver saberes frente as práticas culturais desenvolvendo participação social.

Tendo em vista os desafios da gestão da educação não formal frente as teorias e práticas da gestão democrática, para Sales (2013, p.29) "Os desafios que apresentam para a atuação do gestor dizem respeito as novas exigências de mudança estrutural, comportamental e cultural da atualidade". Partindo de uma gestão democrática com o intuito de influenciar na atuação da gestão pedagógica.

A gestão escolar pedagógica e democrática na atualidade supõe uma dinâmica com foco no sócio construtivista, pessoal e social, ligado ao conhecimento cultural prévio da comunidade 
trabalhada ou público alvo, dessa forma os envolvidos na cultura que fazem parte das experiências de vida, se desenvolvem em todo o contexto escolar e da comunidade, que venha promover o ensino e aprendizagem para formação efetiva do educando. Portanto é um desafio promover uma educação voltada para o aluno dentro dos eixos estruturais e metódicos atribuídos a educação não formal e assim desenvolver as habilidades objetivadas em uma gestão pedagógica que atenda a necessidade do público. De acordo com Sales:

Pensar na gestão escolar numa perspectiva democrática pressupõe hoje, conhecer mais do que sua dinâmica objetiva e o contexto sócio cultural em que se insere. É preciso compreendê-la como um local onde seus agentes são instituístes de uma cultura, dependendo de suas experiências subjetivas, de suas interações sociais, seus objetivos, interesses crenças e valores que se manifestam nos diferentes modos de pensar, sentir e agir no cotidiano da escola e, em especial das suas práticas. (SALES, 2013, p. 25)

Diante da influência do meio em que se trabalha as relações sociais é levado em consideração as múltiplas abordagens de inversão do indivíduo ao meio social. Para Sales (2013, p.28) “ $\mathrm{Na}$ análise do papel do meio na construção do indivíduo compreendem-se todas as situações vividas pelo aluno no espaço cultural, seu cotidiano e suas relações sociais e suas experiências". As atitudes das comunidades em meio aos projetos desenvolvidos pela instituição não formal podem influenciar no processo de ensino e aprendizagem, seja de forma negativa ou positiva.

Para a realização da sua atuação e gestão do exercício no campo não formal são necessários alguns elementos, como as capacidades no que diz respeito a fundamentação e formação profissional, que favorece de forma significativa no processo de inserção e permanência dos cidadãos em todos os níveis de extensão do atendimento, sejam crianças, jovens adultos ou idosos, pois o campo de atuação pedagógico além de vasto atende diversas faixas etárias. $\mathrm{Na}$ perspectiva de Silva e Perrude (2013):

I-conhecimento da realidade da comunidade com a qual irá trabalhar; 2necessidade de propostas que contemplem objetivos pedagógicos explícitos com relação ao ato educativo; 3 - observação das necessidades da comunidade envolvida, numa proposta fundamentada e sempre sistematizada; 4- clareza da ação - É preciso que se explicitem, num processo de conquista, também os pressupostos da ação do educador (compromisso social e político) [...] (SILVA E PERRUDE, 2013, p.54)

A pedagogia e gestão nos espaços não escolares trabalha-se através de projetos de reintegração e recriação do indivíduo social. Para Santos, Dantas e Bezerra (2018, p.4) "A proposta da educação não-formal é criar espaços para atender a necessidade de inclusão social de crianças e adolescentes e sua família, por meio de projeto”. Os projetos têm por objetivo atender as necessidades da comunidade, são desenvolvidos em conjunto com atividades educativas de 
assistência cultural e recreativas com o intuito social e cognitivo.

Os projetos educativos exercidos nos campos não escolares, possibilita ao indivíduo desenvolver habilidades para atuar nas suas atividades em comunidade e na solução de problemas, capaz de tornar pessoas responsáveis e emancipada de suas ações. Para Santos, Dantas e Bezerra (2018, p.4) "Nessa concepção, a educação possibilita e habilita os indivíduos a se organizarem com ações comunitárias, voltadas para a solução de problemas coletivos cotidianos”. Portanto, os projetos contribuem em meio as ações para uma educação significativa e construtivista.

Dentre os desafios e possibilidades abordadas é possível denominar o papel pedagógico na gestão dos espaços não escolares em diversos campos distintos e o desafio do reconhecimento social e a relação da atuação pedagógica em âmbito não formal. Portanto se faz necessário a discursão dos desafios e possibilidades que essa modalidade trouxe para a educação tradicional buscando modificar o ensino para que possa atender melhor a sociedade de forma integral.

\section{METODOLOGIAS}

A pesquisa parte do método de abordagem classificada como qualitativa de acordo com a perspectiva de Prodanov e Freitas (2013, p.7o) "Esta não requer o uso de métodos e técnicas estatísticas. $\mathrm{O}$ ambiente natural é a fonte direta para coleta de dados e o pesquisador é o instrumento-chave". A investigação acontece através das evidencias dos fatos investigados referente ao tema.

Conforme os objetivos abordados a pesquisa se caracteriza como descritiva de acordo com Prodanov e Freitas (2013, p. 52) "Nas pesquisas descritivas, os fatos são observados, registrados, analisados, classificados e interpretados, sem que o pesquisador interfira sobre eles". Dessa forma o pesquisador não interfere nos resultados, apenas registra e descreve.

De acordo com os procedimentos a pesquisa se caracteriza como bibliográfica, segundo Silva e Menezes (2005, p. 21) "quando elaborada a partir de material já publicado, constituído principalmente de livros, artigos de periódicos e atualmente com material disponibilizado na Internet". Assim englobando o assunto estudado através de fundamentação teórica.

A escolha das obras se deu através da seleção mediante ao tema investigado na pesquisa, foram utilizados artigos científicos, periódicos, livros da biblioteca da Universidade Estadual do Tocantins (Unitins). O critério de escolha se deu por meio da relação com a problemática investigada. 


\section{CONSIDERAÇÕES FINAIS}

A atuação do pedagogo em espaços não escolares na perspectiva abordada neste trabalho tem como principal finalidade refletir sobre o papel do pedagogo frente a gestão das atividades exercidas no campo não formal de atuação dentre as possibilidades e desafios encontrados. Para isso ele se mune de ferramentas didáticas e teóricas, podendo atuar na sala de aula e fora dela, com o objetivo de formar cidadãos críticos, atuando principalmente com a parcela mais vulnerável da sociedade.

Neste sentido, entendesse que o pedagogo como mediador na gestão das atividades no campo não formal é de fundamental importância para o desenvolvimento global do indivíduo, que surgiu para atender a necessidade de levar a educação além do âmbito escolar de forma complementar a educação formal. Diante das atividades desenvolvidas pelo pedagogo frente a sua atuação em espaços não escolares, trazendo possibilidades e reafirmado as potencialidades para a transformação social e significativa do sujeito.

Desta forma, é notório a necessidade deste profissional como um mediador, investigador e pesquisador do campo educacional e extraescolar. O gestor desse espaço possui diversas possibilidades de atuação no campo não formal, assim como se põem de forma abrangente também se restringe, pois, a sociedade precisa entender o papel do pedagogo fora dos âmbitos formais, a formação pedagógica não se limita estreitamente aos campos formais de educação. $O$ pedagogo precisa assumir a função dos seus campos de forma efetiva.

Portanto, o pedagogo oferece a sociedade uma educação formativa, didática e democrática ocupando o tempo ocioso da criança, adolescente, adulto ou idoso, diminuindo os índices de criminalidades e evasão escolar, essa modalidade de educação se posiciona de forma complementar a educação formal sem o intuito de substitui-la, trabalhando o sujeito de forma global e emancipatória dentro das suas capacidades, desenvolvendo suas habilidades, promovendo bem-esta e qualidade de vida. Possibilitando ao indivíduo se sentir parte da sociedade como ser ativo e capacitado a se posicionar frente as adversidades.

\section{REFERÊNCIAS BIBLIOGRÁFICAS}

ALMEIDA, M. S. OLIVEIRA, S. S. Educação não formal, informal e formal do conhecimento científico nos diferentes espaços de ensino e aprendizagem. In: OS DESAFIOSDA ESCOLAPÚBLICAPARANAENSE NAPERSPECTIVA DO PROFESSOR PDE PRODUÇÕES DIDÁTICO-PEDAGÓGICAS- PDE, Produções Didáticos-Pedagógicos. Cadernos programa de desenvolvimento educacional-PDE. Paraná, V.II.n. p.oı-18, 2014.Versão Online ISBN 978-85-8015-079-7. Disponível em:http://www.diaadiaeducacao.pr.gov.br/portals/cadernospde/pdebusca/producoes_pde/2oI 4/2014_uel_bio_pdp_maria_salete_bortholazzi_almeida.pdf. Acesso em:13/II/2o. 
ANTKIEWICZ, D, A. COSTA, D, C. O Papel do Pedagogo em Espaços não Formais. Revista científica FAZER. Erechim, v.7, n.I. p. 73-79, 2019. Disponível em:https://portal.fslf.edu.br/wpcontent/uploads/2016/ı2/Pedagogos_em_espacos_nao_escolare s.pdf. Acesso em: 13/11/20.

ANELO, G.; SOUZA, A. Aprendizagem no espaço não escolar. Revista e - Ped FACOS/CNECO Osório v o 1. 2 - n ${ }^{\circ}$ 1, 2012 - ISS $\mathrm{N}^{\circ}$ 2, p. 37 - 7077.Disponivel em: http://facos.edu.br/publicacoes/revistas/eped/agosto_2012/pdf/aprendizagem_no_espaco_nao_ escolar.pdf acesso em: 19/10/20.

BRASIL. Ministério da Educação Concelho Nacional de Educação Conselho Pleno, Resolução no 2, de $\mathbf{I}^{\circ}$ de julho de 2015, Brasília. DF, 2015.

BRASIL, LDB passo a passo lei de diretrizes e bases nacional lei $\mathrm{n}^{\circ} \mathbf{9 . 3 9 4 / 9 6}$ comentada $\mathrm{e}$ interpretada artigo por artigo. Brasília, DF, 2007.

DIAS, Renan Italo Rodrigues. Gestão escolar: Os processos e dificuldades do gestor escolar. Revista Científica Multidisciplinar Núcleo do Conhecimento. 2019, Ed. o6, Vol. 07, p. 13-20. ISSN: 2448-0959. Disponível em: https://www.nucleodoconhecimento.com.br/educacao/processos-e-dificuldades acesso em: I4/10/20

FALCO, A, M. C MOREIRA, J, A. A GESTÃO DO TRABALHO PEDAGÓGICO EM ESPAÇOS ESCOLARES E NÃO ESCOLARES: UM DEBATE ACERCA DA FORMAÇÃO DO PEDAGOGO NO BRASIL, B. Téc. Senac, Rio de Janeiro, v. 43, n. I, p. 256-273, jan./abr. 2017. Disponível em: https://www.researchgate.net/publication/328979373 acesso em: 19/1o/20.

FREIRE, P, R. Pedagogia da autonomia: saberes necessários à prática educativa, $25^{\circ} \mathrm{ed}$. São Paulo: Paz e Terra, 1996.

FILHO, V, S. CONTRERAS, H, S. A atuação do Pedagogo no Terceiro Setor: desafios na formação. Seminário Internacional de Representações Sociais, Subjetividades e Educação, In: CONGRESSO NACONAL DE EDUCAÇÃO EDUCERE.X., p. oı-I3. 2oII, Curitiba ISSN: 2176-1396. Disponível em: https://educere.bruc.com.br/CD2oII/pdf/4488_3754.pdf. Acesso em: 20/10/20

FERREIRA, H, P; MEDEIROS, N, F. As práticas pedagógicas nos espaços não escolares: contextos, sujeitos e aprendizagens. In: COLÓQUIO INTERNACIONAL EDUCAÇÃO E CONTEMPORANEIDADE, VI, 20I2, São Cristovam p. oI-I4. Disponível em: http://educonse.com.br/2012/eixo_19/PDF/22.pdf Acesso em: 19/10/20.

GONÇALVES, J. P. CORREIA, A, M. O pedagogo em âmbitos não escolares: perspectivas, entraves e possibilidade de atuação em empresas. Rev. educ. PUC-Camp, Campinas, V. 2 I n. 2, p.193-209, 2016. Disponível em: http://periodicos.puccampinas.edu.br/seer/index.php/reveducacao/article/download/2821/2288. Acesso em: $20 / \mathrm{II} / 20$.

GOHN, M, G. Educação não-formal, participação da sociedade civil e estruturas colegiadas nas escolas. Ensaio: aval. pol. públ. Educ., Rio de Janeiro, v.I4, n.5o, p. 27-38,. 2006. Disponível em:https://www.scielo.br/pdf/ensaio/vi4n5o/30405.pdf. Acesso em: 29/ro/20. 
LOPES, A, C, F. et al. A educação não formal: um espaço alternativo da educação in: CONGRESSO NACIONAL DE EDUCAÇAO-EDCERE, FORMAÇÃO DE PROFESSORES; CONTEXTOS, SENTIDOS E PRATICAS, XIII, 2or7, Curitiba. p.oi-I2. Disponível em: https://educere.bruc.com.br/arquivo/pdf2017/25198_12669.pdf . Acesso em: 22/10/20.

\section{LIBÂNEO, J, C. Pedagogia e Pedagogos, Para Quê?. 2 ed. São Paulo, Cortez 1999.}

LIBÂNEO, J, C. Organização e Gestão da Escola: teoria e prática, 5 ed. Goiânia: editora alternativa, 2004.

MARQUES, T, G. Formação de pedagogos e o estágio em espaços não formais: uma análise da pesquisa como possibilidade In: Encontro Nacional de Didática e Práticas de Ensino - UNICAMP, XVI., 2012, Campinas: ENDIPE, 2012. p. or-1o. Disponível em: http://endipe.pro.br/ebooks-2012/2423d.pdf Acesso em:28/o9/20.

NASCIMENTO, A, S. A atuação do pedagogo em espaços não escolares: desafios e possibilidades. Pedagogia em Ação, v. 2, n. I, p. I-103, 2010. Disponível em: http://periodicos.pucminas.br/index.php/pedagogiacao/article/view/. Acesso em: 15/10/20.

PRODANOV, C, C. FREITAS, E, C. Metodologia do trabalho científico [recurso eletrônico]: métodos e técnicas da pesquisa e do trabalho acadêmico. 2. ed. Novo Hamburgo: Feevale, 2013. Disponivel em: http://www.feevale.br/Comum/midias/88o7fo5a-I4do-4d5b-bradI538f 3 aef538/E-book\%20Metodologia\%2odo\%20Trabalho\%20Cientifico.pdf. Acesso em: 05/ II/20

PEREIRA, C, S. Pedagogia em Espaços não Escolares. 20ı6. Dissertação (Curso de Pedagogia)Faculdade de Pará de Minas - FAPAM. Pará de Minas. Disponível em: http://fapam.ddns.net:8085/admin/monografiasnupe/arquivos/20072017204046Simone_Conce icao_de_Souza_Pereira.pdf. Acesso em: I9/II/20.

REIS, G, M. Pedagogo em espaços não escolares: desafios e possibilidades. 2013. Dissertação (Curso de Licenciatura em Pedagogia) - Faculdade de Educação, Faculdade de Educação da Universidade de Brasília, Brasília. Disponível em: https://bdm.unb.br/bitstream/ro483/7375/1/2013_GrazielleMatosdosReis.pdf. Acesso em: I4/ Io/ 20 .

SANTOS, W, L. O papel do pedagogo dentro do sistema penitenciário. Revista Científica da FASETE, São Francisco, v. IX, $\mathrm{n}$ 9, 103-113, 2015. Disponível em: https://www.unirios.edu.br/revistarios/media/revistas/2015/9/o_papel_do_pedagogo_dentro_ do_sistema_penitenciario.pdf. Acesso em:20/10/20.

SEVERO, J, L. Educação não escolar como campo de práticas pedagógicas. Rev. bras. Estud. pedagog. (online), Brasília, v. 96, n. 244, p. 561-576. 2015. Disponível em: https://www.scielo.br/scielo.php?pid=S217666812015000300561\&script=sci_abstract\&tlng=pt. Acesso em: 30/10/20.

SALES, R.; Gestão da educação em espaços não escolares: possibilidades e desafios de uma pratica vivida.2013. Dissertação (Pós-graduação a distância especialização Lato-Senso em Gestão Educacional) - Universidade Federal de Santa Catarina, Santa Catarina. Disponível em: https://repositorio.ufsm.br/bitstream/handle/I/648/Sales_Rosemeri_de.pdf?sequence $=$ I\&isAll 
owed=y Acesso em: 05/II/20.

SILVA, A, L. PERRUDE, M, R. Atuação do pedagogo em espaços não-formais: algumas reflexões. Revista Eletrônica das Licenciaturas, Londrina, V. I, n. 4, p. I-II, 2013. Disponível em: http://www.uel.br/revistas/prodocenciafope/pages/arquivos/Volume4/TEXTO\%205\%20\%20p.\%2046\%20a\%2056.pdf. Acesso em: 28/ı/20.

SANTOS, A, P. DANTAS, V, M. BEZERRA A, A. Um novo olhar para educação não-formal: sesc projeto caravana da esperança. A formação, ética estética e política de professores da educação básica. In: CONGRESSO ENFOPE I2 FOPIE. v. II, n. I, 2018. Aracaju Sergipe p. I-24. Disponível em: https://eventos.set.edu.br/index.php/enfope/article/download/8889/4055. Acesso em: 28/10/20.

SILVA, E, L. MENEZES, E, M. Metodologia da pesquisa e elaboração de dissertação, 4. ed. rev. atual. Florianópolis: UFSC, 2005.

TAVARES, M, C. DIAS, M, D. ARAUJO, C, M. A atuação do pedagogo em espaços não formais de educação: um estudo a partir de Organizações Não Governamentais do Recife. 2015. DISERTAÇÃO (CURSO DE PEDAGOGIA) - Centro de Educação UFPE, Universidade Federal de Pernambuco, Pernambuco. Disponível em: https://www.ufpe.br/documents/39399/2406246/TAVARES\%3B+DIAS\%3B+ARAU\%C2\%B 4JO+-+2015.I.pdf/fo6rinic-b996-4987-92c7-6f683519d5a. Acesso em:I4/ri/2o. 